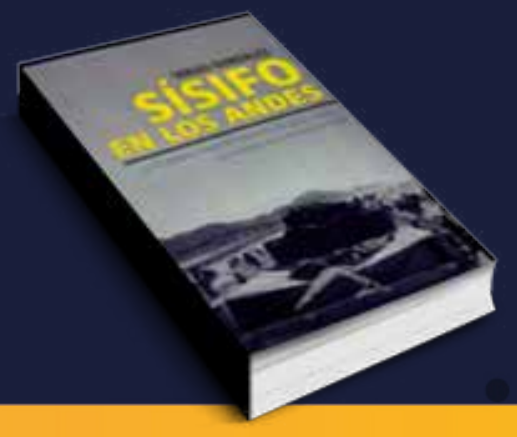

\title{
Reseña
}

\section{Sísifo en los Andes. La (frustrada) integración física entre Tarapacá y Oruro. Las caravanas de la amistad de 1958}

GONZÁLEZ, Sergio

por Estefanía Bianchi*

Edición: RIL Editores, Santiago de Chile, 2012 | 137 Páginas

El trabajo realizado por Sergio González expone los intentos de integración física transfronteriza entre las poblaciones de las regiones de Tarapacá (Chile) y Oruro (Bolivia), reparando particularmente en las caravanas de la amistad que en 1958 unieron las localidades de Oruro e Iquique, como testimonio de una voluntad históricamente sostenida.

Tratándose de regiones contiguas de países limítrofes con históricos desencuentros en materia territorial, los bríos integracionistas de sus poblaciones revisten gran interés. Los antecedentes de esta relación se remontan a la época colonial, cuando se establecieron vías de comunicación alternativas a las dispuestas por la colonia para estructurar la economía de la plata. Tras la independencia, y en el marco de las economías del nitrato y el estaño, se desarrollaron varios proyectos ferroviarios (1864-1928) que naufragaron debido al resquemor sostenido entre los gobiernos centrales. Sin embargo, la esperanza en la integración no claudicó y desde la tercera década del Siglo XX se han impulsado iniciativas para construir una carretera de carga pesada. Han sido éstas las que inspiraron las caravanas de la amistad de 1958, que constituyen el tema central del trabajo.

El libro se compone de cuatro capítulos, apoyados en una rica documentación fotográfica. El primero describe la relación bilateral entre Chile y Bolivia a lo largo de la década de 1950. En un decenio dorado en términos diplomáticos, pero un tanto oscuro en términos económicos (especialmente para las regiones en cuestión), la construcción del camino Iquique-Oruro fue incluido en principio- en las agendas de los gobiernos centrales.

El segundo capítulo expone la gestación e inicio de las caravanas de la amistad en 1958. Las promesas y asignaciones presupuestarias de los gobiernos centrales por un lado, y por el otro el retraso en la construcción de la carretera, generaron sentimientos encontrados en las poblaciones de Oruro e Iquique y las llevaron a demostrar la necesidad y factibilidad de la integración física.

El tercer capítulo detalla la experiencia de la primera caravana: aquella que partió de Oruro y arribó a Iquique un 21 de mayo, Día de las Glorias Navales chilenas. Le esperaba una cálida acogida, numerosos agasajos y un fructífero intercambio comercial. Todos estos aspectos son expuestos con sumo detalle por el autor.

El cuarto capítulo describe la experiencia de la segunda comitiva, la iquiqueña, que alcanzó Oruro horas antes del 6 de Agosto, Día de la Independencia de Bolivia. La bienvenida replicó lo ocurrido en Chile: agasajos, intercambio comercial y cultural. En esta sección, el autor también describe la lógica de relacionamiento transfronterizo que siguió a las caravanas: tras ellas, se realizaron otros viajes, todos de carácter cultural, pues el aspecto comercial fue relegándose conjuntamente a la posibilidad de contar con la tan ansiada carretera internacional. En las últimas décadas, la frustración respecto de aquélla probablemente se vio compensada por la esperanza en el corredor bioceánico.

El mito de Sísifo ilumina la histórica voluntad de integración transfronteriza entre las poblaciones de las regiones de Oruro y Tarapacá. Lo frustrado de la empresa nunca ha sepultado las esperanzas. Una y otra vez el esfuerzo se ha renovado. Las caravanas de la amistad de 1958 han sido, quizás, el mayor símbolo de este "círculo eterno".

* Licenciada en Relaciones Internacionales (Universidad Nacional de Rosario, Argentina), Maestranda en Integración y Cooperación Internacional (CERIR-CEI-UNR). 